\title{
CALCULATION OF THE LHC-KICKER BEAM IMPEDANCE*
}

\author{
Glen R. Lambertson \\ Lawrence Berkeley National Laboratory \\ Berkeley, California 94720
}

\section{Abstract}

Longitudinal and transverse beam impedances are calculated for the injection kickers designed for use in the CERN large hadron collider. These combine the contributions of a ceramic beam tube with conducting stripes and a travelingwave kicker magnet. The results show peak impedances of $1300 \mathrm{ohm}$ longitudinal and $8 \mathrm{M} \Omega / \mathrm{m}$ transverse for four units per ring.

\section{INTRODUCTION}

The design for the LHC calls for four injection-kicker units for each beam[1], each unit is a c-magnet with an alumina beam tube, shown schematically in Fig. 1. Thirty conducting stripes are applied inside the beam tube (See Table 1); each of these connects to the continuing metal tube through R-C networks. The impedances $Z_{L}$ of this liner and $Z_{M}$ of the magnets are combined in parallel to give the total impedance $Z_{B}$.

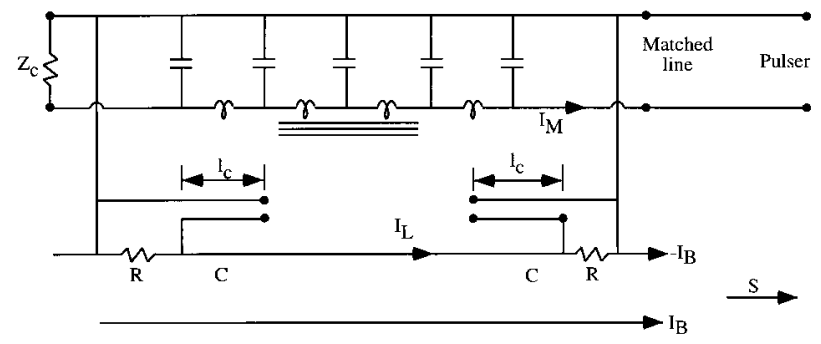

Figure 1: Schematic of circuits in kicker magnet with liner. $I_{B}$ is the beam current.

\section{LINER LONGITUDINAL IMPEDANCE}

A metallized outer sleeve on the ceramic tube overlaps the inner stripes by about $0.28 \mathrm{~m}$ to provide $600 \mathrm{pF}$ capacitance. Calculated as an open-ended transmission line this capacitor's impedance is $\left[j C \frac{v_{c}}{\ell_{c}} \tan \frac{\omega \ell_{c}}{v_{c}}\right]^{-1}$. The stripes on the ceramic contribute a small inductance; this has been calculated to be only 6.5 pico-henry. Combining the liner's components, the liner impedance becomes

\footnotetext{
* Work supported by the U.S. Dept of Energy under Contract No. DEAC03-76SF00098.

${ }^{\text {a }}$ More details of these calculations are given in Ref. [2]
}

Table 1: Liner Parameters

$\begin{array}{lcl}\text { Tube inner radius } & \mathrm{b} & 21 \mathrm{~mm} \\ \text { Ceramic well thickness } & & 4 \mathrm{~mm} \\ \text { Relative dielectric constant } & \epsilon_{r} & 9 \\ \text { Number of stripes } & \mathrm{N} & 30 \\ \text { Length of stripe } & \ell_{s} & 3540 \mathrm{~mm} \\ \text { Width of stripe } & \mathrm{W} & 4 \mathrm{~mm} \\ \text { Space between stripes } & \mathrm{a} / 2 & 4 \mathrm{~mm} \\ \text { Capacitance (30 stripes, one end) } & \mathrm{C} & 600 \mathrm{pF} \\ \text { Length of capacitor line } & \ell_{c} & 280 \mathrm{~mm} \\ \text { Phase velocity along capacitor } & v_{c} & \sim 0.385 \mathrm{c} \\ \text { Resistance (5000/30) } & \mathrm{R} & 169 \mathrm{ohm}\end{array}$

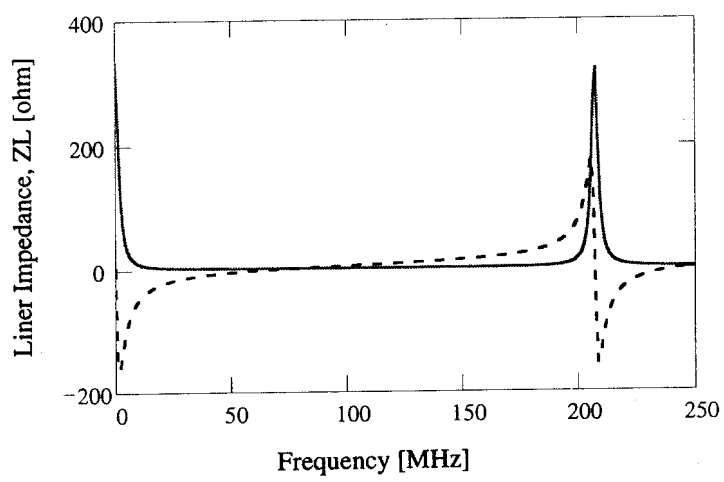

Figure 2: Impedance of the liner. Solid $-\operatorname{Re} Z_{L}[\mathrm{Ohm}]$. Dashed $-\operatorname{Im} Z_{L}[\mathrm{ohm}]$.

$$
\begin{aligned}
Z_{L} & =\frac{2}{\frac{1}{R}+j \frac{C v_{c}}{\ell_{c}} \tan \frac{\omega \ell_{c}}{v_{c}}} \\
& +j \frac{\omega \mu_{0} \ell_{s}}{2 \pi N} \frac{\epsilon_{r}-1}{\epsilon_{r}+1} \quad\left(\csc \frac{\pi \mathrm{w}}{2 a}\right)
\end{aligned}
$$

which is plotted in Fig. 2. We see at intervals of 206 $\mathrm{MHz}$ the impedance maxima that occur when the capacitor length is multiples of one-half wavelength.

\section{IMPEDANCE FROM THE MAGNET}

The portion of the beam current that is not shielded by the liner current $I_{L}$ induces voltages in the magnet. This current $I_{M}=I_{B}+I_{L}$ couples to the magnet in two ways, (1) 
Table 2: Magnet Parameters

$\begin{array}{lcl}\text { Length } & \ell & 2657 \mathrm{~mm} \\ \text { Aperture gap } & \mathrm{g} & 54 \mathrm{~mm} \\ \begin{array}{l}\text { Aperture width } \\ \text { Winding inductance }\end{array} & \mathrm{d} & 54 \mathrm{~mm} \\ \text { per unit length }\left(=\mu_{o}\right) & L^{\prime} & 1.25 \times 10^{-6} \mathrm{Hy} / \mathrm{m} \\ \text { Winding line-impedance } & Z_{c} & 5 \mathrm{ohm} \\ \text { Phase velocity }\left(Z_{c} / L^{\prime}\right) & v & 4 \times 10^{6} \mathrm{~m} / \mathrm{sec} \\ \text { Drive line delay }(\text { example }) & \tau & 0.233 \mu \mathrm{sec}\end{array}$

magnetic images in the yoke and conductors and (2) currents induced in the winding. Parameters of the magnet are given in Table 2 and the geometry of its square aperture in Fig. 3.

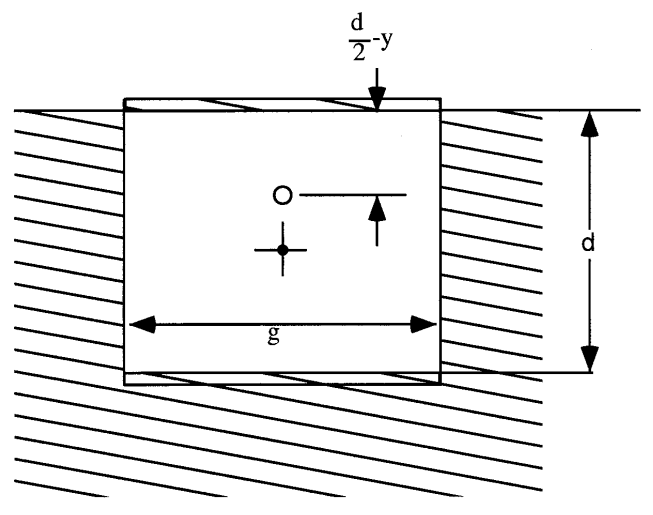

Figure 3: Aperture of the magnet bounded by winding conductors at $Y= \pm d / 2$. Current $I_{M}$ is shown at distance $y$ from the center.

Coupling to the yoke has been calculated by summing the fields of image currents in the ferrite and in the conductor surfaces. This gives an inductance of $0.317 \mathrm{~L}^{\prime} \ell$.

To calculate the mutual coupling to the winding one must consider in detail the propagation of induced currents in the winding and reflection or absortion at the ends of the winding circuit [2][3]. The drive line is assumed to be open at the pulser; the other end is impedance-matched by terminator $Z_{c}$. In an increment of length $d s$, the mutual inductance between beam and winding is

$$
M^{\prime} d s=\mu_{0} \frac{\frac{d}{2}-y}{g} d s
$$

Currents induced by this coupling propagate away from $d s$ at velocity $v$. Integrating over the winding length we obtain the directly-induced current

$$
I=-I_{M} \frac{v L^{\prime}}{2 Z_{c}}\left(1-\frac{2 y}{d}\right)\left(1-e^{-\frac{k \ell}{2}} \cos k s\right)
$$
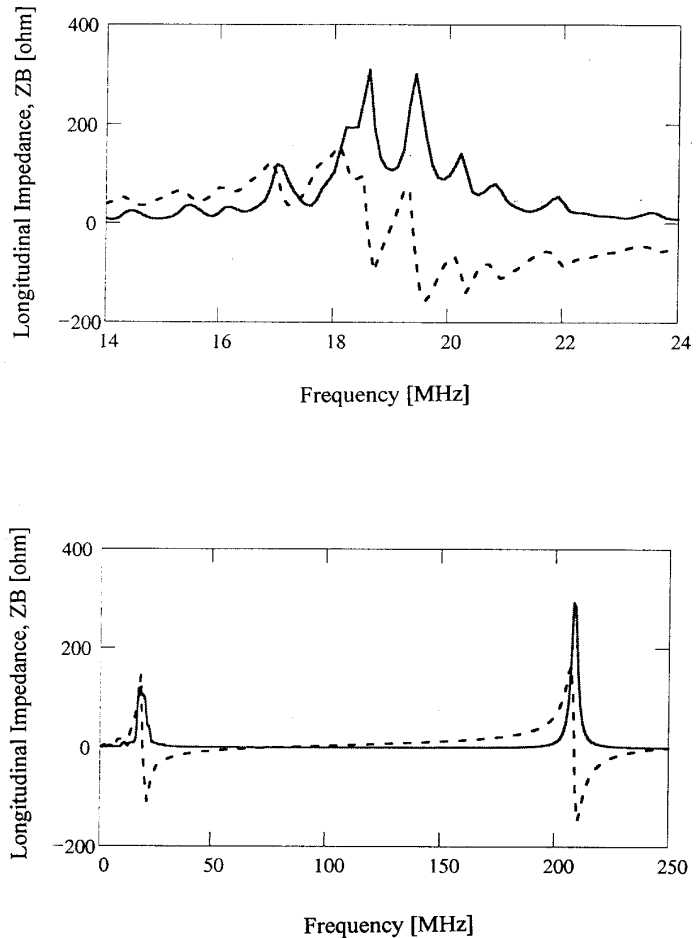

Figure 4: Total longitudinal impedance. Solid $-\operatorname{Re} Z_{B}$ [ohm]. Dashed $-\operatorname{Im} Z_{B}[\mathrm{ohm}]$.

where $k=\omega / v$. This is then reflected at the pulser and the resultant net current induces at the beam positron $y$ (Fig. 3) the voltage (Here $\theta=\frac{k \ell}{2}$ )

$$
\begin{aligned}
& V=\frac{I_{m} Z_{c}}{2}\left(1-\frac{2 y}{d}\right)^{2} \\
& {\left[j \theta-e^{-j \theta} j \sin \theta+e^{-j 2(\omega \tau+\theta)} \sin ^{2} \theta\right]}
\end{aligned}
$$

Adding to this the voltage from the yoke we get from the magnet the impedance at aperture center

$$
\begin{aligned}
Z_{M}= & \frac{Z_{L}}{2}\left[0.268 j \theta+e^{-j \theta} j \sin \theta\right. \\
& \left.-e^{-j 2(\omega \tau+\theta)} \sin ^{2} \theta\right]
\end{aligned}
$$

The total impedance is now the parallel combination of Eq. 1 and Eq. 4 plotted in Fig. 4. In addition to the capacitor resonances at $206 \mathrm{MHz}$ intervals, we see here at $19 \mathrm{MHz}$ a resonance between the liner's capacitance and the magnet's inductance. These peaks are limited to $330 \mathrm{ohm}$ by the series resistors of the liner.

\section{TRANSVERSE IMPEDANCES}

Because the liner is azimuthally symmetric about the beam centerline, its transverse impedance is given in terms of $Z_{L}$ from Eq. 1 as 


$$
Z_{L t}=\frac{2 c}{\omega b^{2}} Z_{L}
$$

Images in the yoke and conductors give zero impedance in the direction $y$ parallel to the pole faces.

In the $x$-direction, images sum to give

$$
Z_{M x}=0.019 j \frac{\mu_{0} c \ell}{g^{2}}
$$

In Eq. 3 we have shown the $y$-dependence of the winding contribution to $Z_{\|}$. The Panofsky-Wenzel theorem allows us to calculate $Z_{y}$ from $Z_{\|}$as

$$
Z_{y}=\frac{c}{\omega} \frac{\partial}{\partial y} \frac{\Delta Z_{\|}}{\Delta y}
$$

This is

$$
\begin{aligned}
& Z_{M y}=\frac{c}{\omega} \frac{2}{d^{2}} Z_{c} \\
& {\left[-j \theta+j e^{-j \theta} \sin \theta-e^{-j 2(\omega \tau+\theta)} \sin ^{2} \theta\right]}
\end{aligned}
$$

Combining contributions to the transverse impedances, the totals are shown in Figs. 5 and 6 . The $2 M \Omega / m$ peak in $Z_{x}$ that appears at $40 \mathrm{MHz}$ is a resonance between liner and magnet. $Z_{y}$ is strongest at low frequency where at orbital frequency, $11.2 \mathrm{kHz}$, it is $169-\mathrm{j} 3.40 \times 10^{3} \mathrm{ohm} / \mathrm{m}$.

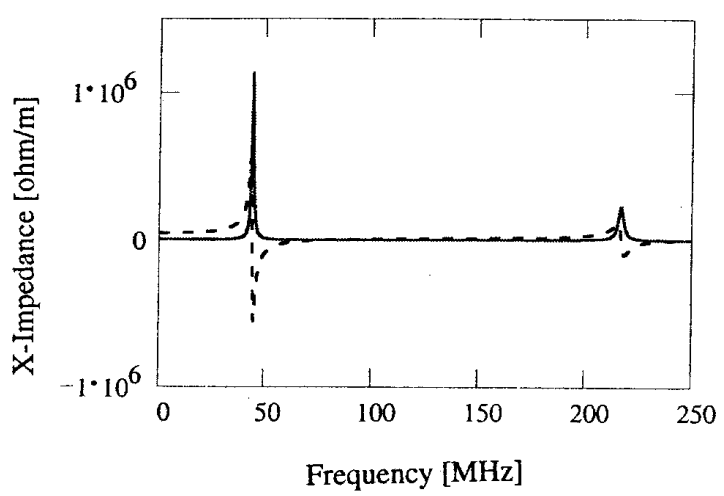

Figure 5: Total horizontal impedance. Solid $-\operatorname{Re} Z_{x}$. Dashed $-\operatorname{Im} Z_{x}$.
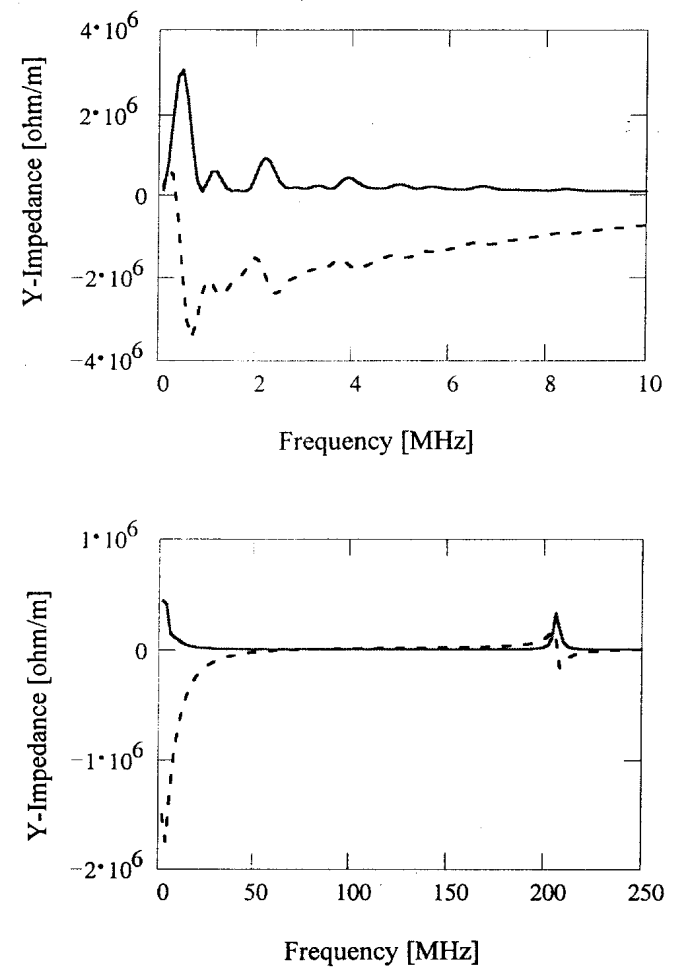

Figure 6: Total vertical impedance. Solid $-R e Z_{y}$. Dashed $-\operatorname{Im} Z_{y}$.

\section{REFERENCES}

[1] L. Ducimetière, U. Jansson, G. H. Schröder, E. B. Vossenberg, M. J. Barnes, G. D. Wait, "Design of the Injection Kicker Magnet System for CERN's $14 \mathrm{TeV}$ Proton Collider LHC," 10th IEEE Pulsed Power Conference, Albuquerque, NM, July $10-13,1995$.

[2] G. R. Lambertson, "LHC Kicker Beam-Impedance Calculation," LBNL-42838, CBP Note-283, October 1998.

[3] W. R. Smythe, Static and Dynamic Electricity, McGraw Hill, New York, 1939, p. 89. 